\title{
National images and international systems
}

\section{K. E. BOULDING}

\section{University of Michigan}

An international system consists of a group of interacting behavior units called "nations" or "countries," to which may sometimes be added certain supra-national organizations, such as the United Nations.

Each of the behavior units in the system can be described in terms of a set of "relevant variables." Just what is relevant and what is not is a matter of judgment of the system-builder, but we think of such things as states of war or peace, degrees of hostility or friendliness, alliance or enmity, arms budgets, geographic extent, friendly or hostile communications, and so on. Having defined our variables, we can then proceed to postulate certain relationships between them, suffcient to define a path for all the variables through time. Thus we might suppose, with Lewis Richardson, ${ }^{2}$ that the rate of change of hostility of one nation toward a second depends on the level of hostility in the second and that the rate of change of hostility of the second toward the first depends on the level of hostility of the first. Then, if we start from given levels of hostility in each nation, these equations are sufficient to spell out what hap-

1 This paper was presented to a meeting of the American Psychological Association in Washington, D.C., on August 30, 1958.

2 See Anatol Rapoport, "Lewis F. Richardson's Mathematical Theory of War," Journal of Conflict Resolution, I (September, 1957), 249, for an excellent exposition. pens to these levels in succeeding time periods. A system of this kind may (or may not) have an equilibrium position at which the variables of one period produce an identical set in the next period, and the system exhibits no change through time.

Mechanical systems of this kind, though they are frequently illuminating, can be regarded only as very rough first approximations to the immensely complex truth. At the next level of approximation we must recognize that the people whose decisions determine the policies and actions of nations do not respond to the "objective" facts of the situation, whatever that may mean, but to their "image" of the situation. It is what we think the world is like, not what it is really like, that determines our behavior. If our image of the world is in some sense "wrong," of course, we may be disappointed in our expectations, and we may therefore revise our image; if this revision is in the direction of the "truth" there is presumably a long-run tendency for the "image" and the "truth" to coincide. Whether this is so or not, it is always the image, not the truth, that immediately determines behavior. We act according to the way the world appears to us, not necessarily according to the way it "is." Thus in Richardson's models it is one nation's image of the hostility of another, not the "real" hostility, which determines its reaction. The "image," then, must be thought of as the total cognitive, affective, and evaluative structure 
of the behavior unit, or its internal view of itself and its universe. ${ }^{3}$

Generally speaking, the behavior of complex organizations can be regarded as determined by decisions, and a decision involves the selection of the most preferred position in a contemplated field of choice. Both the field of choice and the ordering of this field by which the preferred position is identified lie in the image of the decision-maker. Therefore, in a system in which decision-makers are an essential element, the study of the ways in which the image grows and changes, both of the field of choice and of the valuational ordering of this field, is of prime importance. The image is always in some sense a product of messages received in the past. It is not, however, a simple inventory or "pile" of such messages but a highly structured piece of information-capital, developed partly by its inputs and outputs of information and partly by internal messages and its own laws of growth and stability.

The images which are important in international systems are those which a nation has of itself and of those other bodies in the system which constitute its international environment. At once a major complication suggests itself. A nation is some complex of the images of the persons who contemplate it, and as there are many different persons, so there are many different images. The complexity is increased by the necessity for inclusion, in the image of each person or at least of many persons, his image of the image of others. This complexity, however, is a property of the real world, not to be evaded or glossed over. It can be reduced to simpler terms if we distinguish between two types of persons in a nation-the powerful, on the one

${ }^{3}$ See K. E. Boulding, The Image (Ann Arbor: University of Michigan Press, 1956), for an exposition of the theory on which this paper is based. hand, and the ordinary, on the other. This is not, of course, a sharp distinction. The power of a decision-maker may be measured roughly by the number of people which his decisions potentially affect, weighted by some measure of the effect itself. Thus the head of a state is powerful, meaning that his decisions affect the lives of millions of people; the ordinary person is not powerful, for his decisions affect only himself and the lives of a few people around him. There is usually a continuum of power among the persons of a society: thus in international relations there are usually a few very powerful individuals in a state-the chief executive, the prime minister, the secretary of state or minister of foreign affairs, the chiefs of staff of the armed forces. There will be some who are less powerful but still influential-members of the legislature, of the civil service, even journalists, newspaper owners, prominent businessmen, grading by imperceptible degrees down to the common soldier, who has no power of decision even over his own life. For purposes of the model, however, let us compress this continuum into two boxes, labeled the "powerful" and the "ordinary," and leave the refinements of power and influence for later studies.

We deal, therefore, with two representative images, (1) the image of the small group of powerful people who make the actual decisions which lead to war or peace, the making or breaking of treaties, the invasions or withdrawals, alliances, and enmities which make up the major events of international relations, and (2) the image of the mass of ordinary people who are deeply affected by these decisions but who take little or no direct part in making them. The tacit support of the mass, however, is of vital importance to the powerful. The powerful are always under some obligation to represent the mass, even under dictatorial regimes. In democratic societies the aggregate influence of the images of ordinary people is very great; the image 
of the powerful cannot diverge too greatly from the image of the mass without the powerful losing power. On the other hand, the powerful also have some ability to manipulate the images of the mass toward those of the powerful. This is an important object of instruments as diverse as the public education system, the public relations departments of the armed services, the Russian "agitprop," and the Nazi propaganda ministry.

In the formation of the national images, however, it must be emphasized that impressions of nationality are formed mostly in childhood and usually in the family group. It would be quite fallacious to think of the images as being cleverly imposed on the mass by the powerful. If anything, the reverse is the case: the image is essentially a mass image, or what might be called a "folk image," transmitted through the family and the intimate face-to-face group, both in the case of the powerful and in the case of ordinary persons. Especially in the case of the old, long-established nations, the powerful share the mass image rather than impose it; it is passed on from the value systems of the parents to those of the children, and agencies of public instruction and propaganda merely reinforce the images which derived essentially from the family culture. This is much less true in new nations which are striving to achieve nationality, where the family culture frequently does not include strong elements of national allegiance but rather stresses allegience to religious ideals or to the family as such. Here the powerful are frequently inspired by a national image derived not from family tradition but from a desire to imitate other nations, and here they frequently try to impose their images on the mass of people. Imposed images, however, are fragile by comparison with those which are deeply internalized and transmitted through family and other intimate sources.

Whether transmitted orally and informally through the family or more formally through schooling and the written word, the national image is essentially a historical image-that is, an image which extends through time, backward into a supposedly recorded or perhaps mythological past and forward into an imagined future. The more conscious a people is of its history, the stronger the national image is likely to be. To be an Englishman is to be conscious of " 1066 and All That" rather than of "Constantine and All That," or "1776 and All That." A nation is the creation of its historians, formal and informal. The written word and public education contribute enormously to the stability and persistence of the national images. The Jews, for instance, are a creation of the Bible and the Talmud, but every nation has its bible, whether formed into a canon or not-noble words like the Declaration of Independence and the Gettysburg Address-which crystallize the national image in a form that can be transmitted almost unchanged from generation to generation. It is no exaggeration to say that the function of the historian is to pervert the truth in directions favorable to the images of his readers or hearers. Both history and geography as taught in national schools are devised to give "perspective" rather than truth: that is to say, they present the world as seen from the vantage point of the nation. The national geography is learned in great detail, and the rest of the world is in fuzzy outline; the national history is emphasized and exalted; the history of the rest of the world is neglected or even falsified to the glory of the national image.

It is this fact that the national image is basically a lie, or at least a perspective distortion of the truth, which perhaps accounts for the ease with which it can be perverted to justify monstrous cruelties and wickednesses. There is much that is noble in the national image. It has lifted man out of the narrow cage of self-centeredness, or even 
family-centeredness, and has forced him to accept responsibility, in some sense, for people and events far beyond his face-to-face cognizance and immediate experience. It is a window of some sort on both space and time and extends a man's concern far beyond his own little lifetime and petty interests. Nevertheless, it achieves these virtues usually only at the cost of untruth, and this fatal flaw constantly betrays it. Love of country is perverted into hatred of the foreigner, and peace, order, and justice at home are paid for by war, cruelty, and injustice abroad.

In the formation of the national image the consciousness of great shared events and experiences is of the utmost importance. A nation is a body of people who are conscious of having "gone through something" together. Without the shared experience, the national image itself would not be shared, and it is of vital importance that the national image be highly similar. The sharing may be quite vicarious; it may be an experience shared long ago but constantly renewed by the ritual observances and historical memory of the people, like the Passover and the Captivity in the case of the Jews. Without the sharing, however, there is no nation. It is for this reason that war has been such a tragically important element in the creation and sustenance of the national image. There is hardly a nation that has not been cradled in violence and nourished by further violence. This is not, I think, a necessary property of war itself. It is rather that, especially in more primitive societies, war is the one experience which is dramatic, obviously important, and shared by everybody. We are now witnessing the almost unique phenomenon of a number of new nations arising without war in circumstances which are extremely rare in history, for example-India, Ghana, and the new West Indian Federation, though even here there are instances of severe violence, such as the disturbances which accompanied partition in
India. It will be interesting to see the effect, if any, on their national images.

We now come to the central problem of this paper, which is that of the impact of national images on the relations among states, that is, on the course of events in international relations. The relations, among states can be described in terms of a number of different dimensions. There is, first of all, the dimension of simple geographical space. It is perhaps the most striking single characteristic of the national state as an organization, by contrast with organizations such as firms or churches, that it thinks of itself as occupying, in a "dense" and exclusive fashion, a certain area of the globe. The schoolroom maps which divide the world into colored shapes which are identified as nations have a profound effect on the national image. Apart from the very occasional condominium, it is impossible for a given plot of land on the globe to to be associated with two nations at the same time. The territories of nations are divided sharply by frontiers carefully surveyed and frequently delineated by a chain of customs houses, immigration stations, and military installations. We are so accustomed to this arrangement that we think of it as "natural" and take it completely for granted. It is by no means the only conceivable arrangement, however. In primitive societies the geographical image is not sharp enough to define clear frontiers; there may be a notion of the rough territory of a tribe, but, especially among nomadic peoples, there is no clear concept of a frontier and no notion of a nation as something that has a shape on a map. In our own society the shape on the map that symbolizes the nation is constantly drilled into the minds of both young and old, both through formal teaching in schools and through constant repetition in newspapers, advertisements, cartoons, and so on. A society is not inconceivable, however, and might even be desirable, in which nations governed 
people but not territories and claimed jurisdiction over a defined set of citizens, no matter where on the earth's surface they happened to live.

The territorial aspect of the national state is important in the dynamics of international relations because of the exclusiveness of territorial occupation. This means that one nation can generally expand only at the expense of another; an increase in the territory of one is achieved only at the expense of a decrease in the territory of another. This makes for a potential conflict situation. This characteristic of the nation does not make conflict inevitable, but it does make it likely and is at least one of the reasons why the history of international relations is a history of perpetual conflict.

The territorial aspect of international relations is complicated by the fact that in many cases the territories of nations are not homogeneous but are composed of "empires," in which the populations do not identify themselves with the national image of the dominant group. Thus when one nation conquers another and absorbs the conquered territory into an empire, it does not thereby automatically change the culture and allegiances of the conquered nation. The Poles remained Polish for a hundred and twenty-five years of partition between Germany, Austria, and Russia. The Finns retained their nationality through eight hundred years of foreign rule and the Jews, through nearly two thousand years of dispersion. If a nation loses territory occupied by disaffected people, this is much less damaging than the loss of territory inhabited by a well-disposed and loyal population. Thus Turkey, which was the "sick man of Europe" as long as it retained its heterogeneous empire, enjoyed a substantial renewal of national health when stripped of its empire and pushed back to the relatively homogeneous heartland of Anatolia. In this case the loss of a disaffected empire actually strengthened the national unit.

The image of the map-shape of the nations may be an important factor affecting the general frame of mind of the nation. There is a tendency for nations to be uneasy with strong irregularities, enclaves, detached portions, and protuberances or hollows. The ideal shape is at least a convex set, and there is some tendency for nations to be more satisfied if they have regularly round or rectangular outlines. Thus the detachment of East Prussia from the body of Germany by the Treaty of Versailles was an important factor in creating the fanatical discontent of the Nazis.

A second important dimension of the national image is that of hostility or friendliness. At any one time a particular national image includes a rough scale of the friendliness or hostility of, or toward, other nations. The relationship is not necessarily either consistent or reciprocal-in nation $A$ the prevailing image may be that $B$ is friendly, whereas in nation $B$ itself the prevailing image may be one of hostility toward $A$; or again in both nations there may be an image of friendliness of A toward B but of hostility of B toward A. On the whole, however, there is a tendency toward both consistency and reciprocation-if a nation A pictures itself as hostile toward B, it usually also pictures B as hostile toward it, and the image is likely to be repeated in B. One exception to this rule seems to be observable: most nations seem to feel that their enemies are more hostile toward thein than they are toward their enemies. This is a typical paranoid reaction; the nation visualizes itself as surrounded by hostile nations toward which it has only the nicest and friendliest of intentions.

An important subdimension of the hostility-friendliness image is that of the stability or security of the relationship. A friendly relationship is frequently formalized as an 
alliance. Alliances, however, are shifting; some friendly relations are fairly permanent, others change as the world kaleidoscope changes, as new enemies arise, or as governments change. Thus a bare fifteen or twenty years ago most people in the United States visualized Germany and Japan, even before the outbreak of the war, as enemies, and after Hitler's invasion of Russia, Russia was for a while regarded as a valuable friend and ally. Today the picture is quite changed: Germany and Japan are valuable friends and allies; Russia is the great enemy. We can roughly classify the reciprocal relations of nations along some scale of friendliness-hostility. At one extreme we have stable friendliness, such as between Britain and Portugal or between Britain and the Commonwealth countries. At the other extreme we have stable hostility-the "traditional enemies" such as France and Germany. Between these extremes we have a great many pairs characterized by shifting alliances. On the whole, stable friendly relations seem to exist mainly between strong nations and weaker nations which they have an interest in preserving and stable hostile relations between adjacent nations each of which has played a large part in the formation of the other.

Another important dimension both of the image and of the "reality" of the nation-state is its strength or weakness. This is, in turn, a structure made up of many elements-economic resources and productivity, political organization and tradition, willingness to incur sacrifice and inflict cruelties, and so on. It still makes some kind of sense to assess nations on a strength-weakness scale at any one time. Strength is frequently thought of in military terms as the ability to hurt an opponent or to prevent one's self from being hurt by him. There are also more subtle elements in terms of symbolic loyalties and affections which are hard to assess but which must be included in any complete picture.
Many arrays of bristling armaments have been brought low by the sheer inability of their wielders to attract any lasting respect or affection. No social organization can survive indefinitely unless it can command the support of its members, and a continuing sense of the significance of the organization or group as such is much more durable a source of support than is the fleeting booty of war or monopoly. The Jews have outlasted an impressive succession of conquerors. These questions regarding the ultimate sources of continuing strength or weakness are difficult, and we shall neglect them in this paper.

In order to bring together the variables associated with each nation or pair of nations into an international system, we must resort to the device of a matrix, as in Figure 1. Here the hostility-friendliness variable is used as an example. Each cell, $a_{i j}$, indicates the degree of hostility or friendliness of nation $I$ (of the row) toward nation J (of the column). For purposes of illustration, arbitrary figures have been inserted on a scale from 5 to -5 , -5 meaning very hostile, 5 very friendly, and 0 neutral.4 A matrix of this kind has many

4 The problem of the measurement of hostility (or friendliness) is a very interesting one which we cannot go into extensively here but which is not so hopeless of solution as might at first sight appear. Possible avenues are as follows: (1) A historical approach. Over a period of years two nations have been at war, threatening war, allied, bound by treaty, and so on. Each relation would be given an arbitrary number, and each year assigned a number accordingly: the average of the years' numbers would be the index. This would always yield a symmetrical matrix-that is, the measure of $\Gamma_{s}$ relation to $J$ would be the same as $J$ 's relation to $I$, or $a_{i j}=a_{j \cdot}$ (2) An approach by means of content analysis of public communications (official messages, newspaper editorials, public speeches, cartoons, etc.). This seems likely to be most immediately useful and fruitful, as it would give current information and would also yield very valuable dynamic informa- 
interesting properties, not all of which can be worked out here but which depend on the kind of restraints that we impose on it. If we suppose, for instance, that the relations of na-

tion about the changes in the matrix, which may be much more important than the absolute figures. The fact that any measure of this kind is highly arbitrary is no argument against it, provided that it is qualitatively reliable-that is, moves generally in the same direction as the variable which it purports to measure-and provided also that the limitations of the measure are clearly understood. It would probably be advisable to check the second type of measure against the more objective measures derived from the first method. The difficulty of the first method, however, is the extreme instability of the matrix. The affections of nations are ephemeral! tions are reciprocal, so that I's attitude toward $J$ is the same as $J$ 's toward $I$, the matrix becomes symmetrical about its major diagonal-that is, the lower left-hand triangle is a mirror image of the upper right-hand triangle. This is a very severe restriction and is certainly violated in fact: there are unrequited loves and hates among the nations as there are among individuals. We can recognize a tendency, however, for the matrix to become symmetrical. There is a certain instability about an unrequited feeling. If $I$ loves $J$ and $J$ hates $I$, then either $J$ 's constant rebuff of I's affections will turn I's love to hate, or $I$ 's persistant wooing will break down $J$ 's distaste and transform it into affection. Unfortunately for the history of human relations,

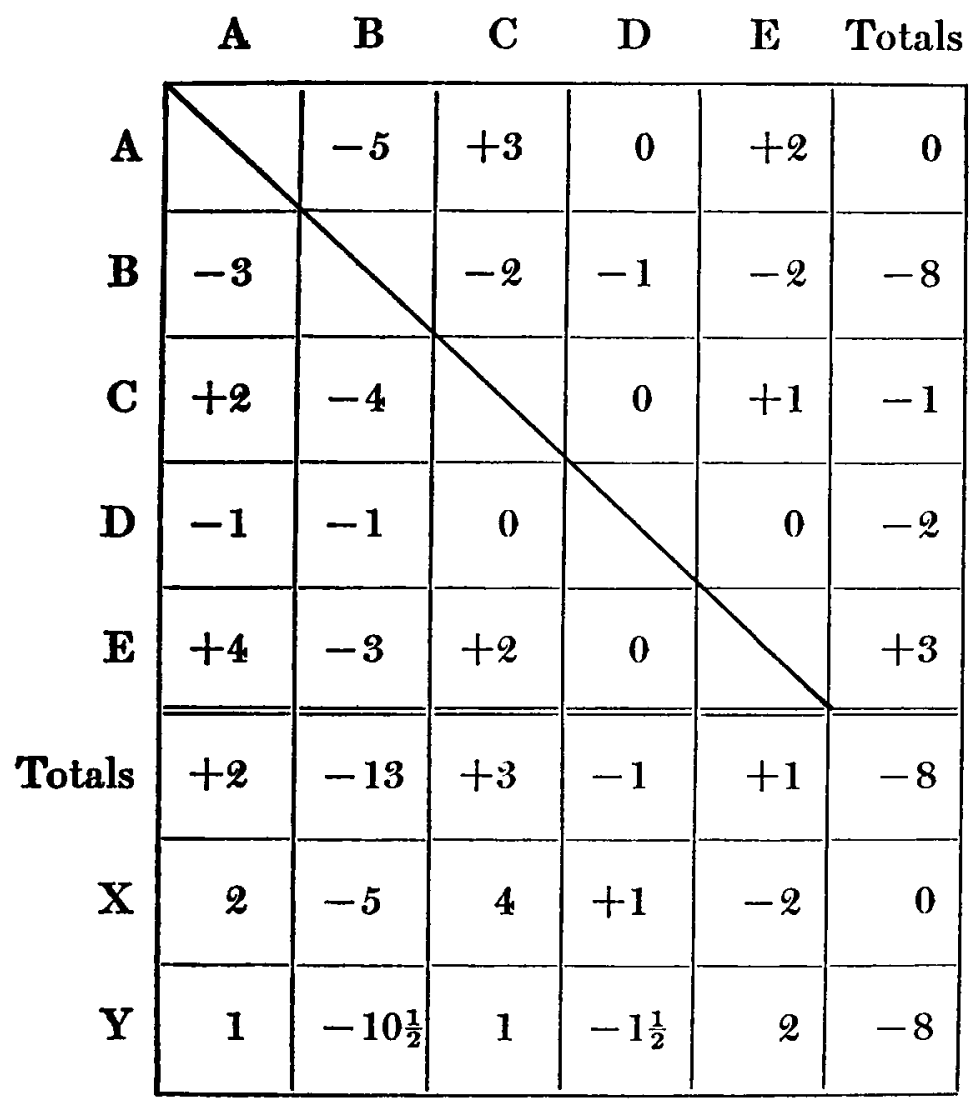

Fic. 1 
the former seems to be the more frequent pattern, but the latter is by no means unknown. ${ }^{5}$

The sum totals of the rows represent the over-all friendliness or hostility of the nation at the head of the row; the sum totals of the columns represent the degree of hostility or friendliness toward the nation at the head of the column. The sum of either of these sums (which must be equal, as each represents a way of adding up all the figures of the matrix) feeling hostile toward everyone and receiving hostility in return; $D$ is a "neutral" nation, with low values for either hostility or friendliness; $E$ is a "friendly" nation, reciprocating $B$ 's general hostility but otherwise having positive relations with everyone. In this figure it is evident that $A, C$, and $E$ are likely to be allied against $B$, and $D$ is likely to be uncommitted.

In the matrix of Figure $l^{\prime}$ no account is

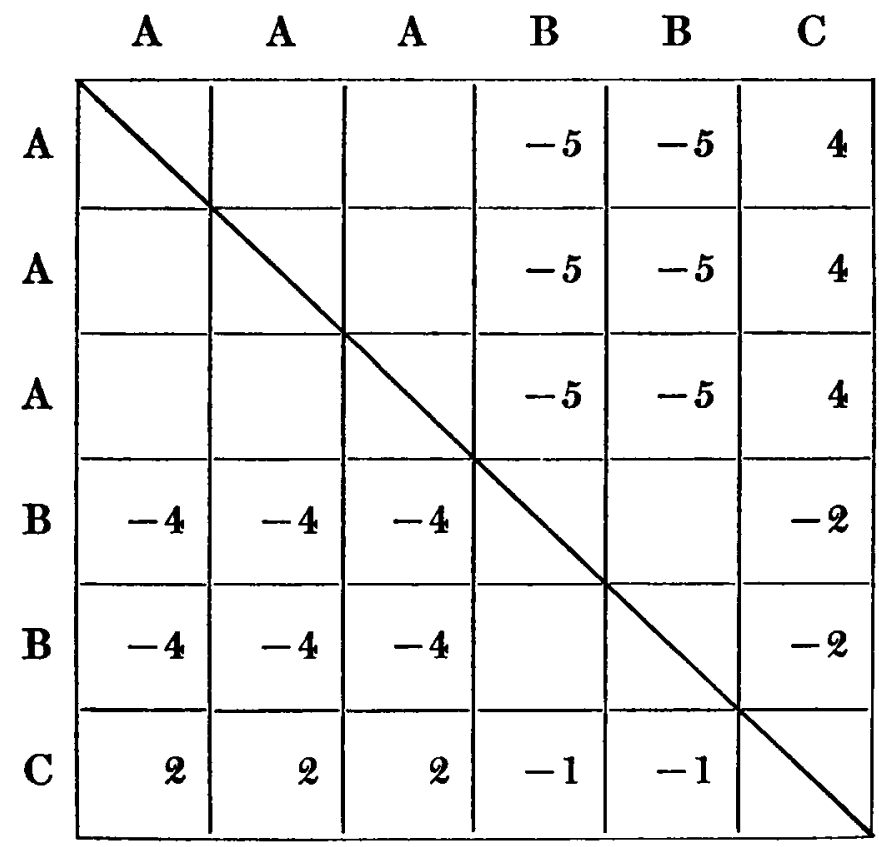

Fig. 2

is a measure of the over-all friendliness or hostility of the system. In the example of Figure 1, $B$ is evidently a "paranoid" nation,

5 George F. Kennan once said: "It is an undeniable privilege of every man to prove himself in the right in the thesis that the world is his enemy; for if he reiterates it frequently enough and makes it the background of his conduct, he is bound eventually to be right" ("The Roots of Soviet Conduct," Foreign Affairs, July, 1947). If for "enemy" we read "friend" in this statement, the proposition seems to be equally true but much less believed. taken of the relative size or power of the different nations. This dimension of the system can easily be accommodated, however. All that is necessary is to take the power of the smallest nation as a convenient unit and express the power of the others in multiples of this unit. Then in the matrix we simply give each nation a number of places along the axes equal to the measure of its power. Thus in Figure 2 we suppose a system of three nations, where $B$ is twice as powerful as $C$ and $A$ is three times as powerful as $C ; A$ is 
then allotted three spaces along the axes, $B$ two, and $C$ one. The analysis of the matrix proceeds as before, with the additional constraint that all the figures in the larger boxes bounded by the lines which divide the nations should be the same, as in the figure.

The difference between the sum of a nation's column, representing the general degree of support or affection it receives, and the sum of a nations row, representing the sum of support or affection it gives, might be called its affectional balance. This is shown in the row $X$ in Figure 1 . It is a necessary property of a matrix of this kind that the sum of all these balances shall be zero. They measure the relative position of each nation in regard to the degree of support it can expect from the international system as a whole. Thus in Figure 1 it is clear that $B$ is in the worst position, and $C$ in the best position, vis-à-vis the system as a whole. Another figure of some interest might be called the affectional contribution, shown in the line $Y$. This is the mean of the column and row totals for each nation. The total affectional contribution is equal to the total of all the figures of the matrix, which measures the general hostility or friendliness of the whole system. The affectional contribution is then a rough measure of how much each nation contributes to the general level of hostility of the whole system. Thus in the example of Figure 1 we see that nation $B$ (the paranoid) actually contributes more than 100 per cent to the total hostility of the system, its extreme hostility being offset to some extent by other nations' friendliness.

One critical problem of an international system, then, is that of the dynamics of the hostility matrix. We can conceive of a succession of such matrices at successive points of time. If there is a system with a "solution," we should be able to predict the matrix at $t_{1}$ from the knowledge we have of the matrix at $t_{0}$ or at various earlier times. The matrix itself will not, in general, carry enough information to make such predictions possible, even though it is easy to specify theoretical models in which a determinate dynamic system can be derived from the information in the matrix alone. ${ }^{6}$

The difficulty with "simple" systems of this nature is that they are very much more simple than the reality which they symbolize. This is because, in reality, the variables of the system consist of the innumerable dimensions of the images of large numbers of people, and the dynamics of the image are much more complex than the dynamics of mechanical systems. This is because of the structural nature of the image; it cannot be represented simply by a set of quantities or variables. Because of this structural nature, it is capable occasionally of very dramatic changes as a message hits some vital part of the structure and the whole image reorganizes itself. Certain events-like the German invasion of Belgium in 1914, the Japanese attack on Pearl Harbor in 1941, the American use of the atom bomb at Hiroshima and Nagasaki, the merciless destruction of Dresden, and the Russian success with Sputnik I-have profound effects and possibly long-run effects on reorganizing the various national images. The "reorganizing" events are hard both to specify and to predict; they introduce, however, a marked element of uncertainty into any dynamic international system which does not exist, for instance, in the solar system!

6 As a very simple example of such a system, let $\left(a_{i j}\right) t$ be a cell of the matrix at time $t$ and $\left(a_{i j}\right) t+1$ be the corresponding value at time $t+1$. Then if for each cell we can postulate a function $\left(a_{i j}\right)_{t+1}=F\left(a_{i j}\right)_{t}$, we can derive the whole $t+1$ matrix from the $t$ matrix. This is essentially the dynamic method of Lewis F. Richardson, and in fairly simple cases it provides an interesting way of formulating certain aspects of the system, especially its tendency toward cumulative movements of hostility (arms races) or occasionally of friendliness. 
In spite of this difficulty, which, oddly enough, is particularly acute in short-term prediction, one gets the impression from the observation of history that we are in the presence of a true system with a real dynamic of its own. We do observe, for instance, cumulative processes of hostility. If we had some measures of the hostility matrix, however crude, it would be possible to identify these processes in more detail, especially the "turning points." There is an analogy here with the business cycle, which also represents a system of cumulative stochastic processes subject to occasional "reorganizations" of its basic equations. Just as we can trace cumulative upward and downward movements in national income, the downward movements often (though not always) culminating in financial crisis and the upward movements often leading to inflation and a subsequent downturn, so we can trace cumulative movements in the hostility matrix. We have "prewar" periods corresponding to downswings, in which things go from bad to worse and hostility constantly increases. The total of all the hostility figures (e.g., -8 on Fig. 1) is a striking analogue of the national-income concept. It might be called the "international temperature." Just as there is a certain critical point in a deflation at which a financial crisis is likely to ensue because of the growing insolvency of heavily indebted businesses, so there is a critical point in the rise of hostility at which war breaks out. This critical point itself depends on a number of different factors and may not be constant. Some nations may be more tolerant of hostility than others; as the cost of war increases, the tolerance of hostility also increases, as we see today in the remarkable persistence of the "cold war." A deflation or downturn, however, may reverse itself without a crisis, and a "prewar" period may turn into a "postwar" period without a war. Indeed, in the period since 1945 we might identify almost as many small interna- tional cycles as there have been business cycles! The "upturn" may be a result of a change of government, the death of certain prominent individuals, or even a change of heart (or imagel) on the part of existing rulers. The catharsis of a war usually produces the typical "postwar" period following, though this is often tragically short, as it was after the end of World War II, when a "downturn" began after the revolution in Czechoslovakia. The downturn is often the result of the reassertion of a persistent, long-run character of the system after a brief interlude of increasing friendliness. There seems to be a certain long-run tendency of an international system toward hostility, perhaps because of certain inescapable flaws in the very concept of a national image, just as there also seems to be a long-run tendency of an unregulated and undisturbed market economy toward deflation.

In considering the dynamics of an international system, the essential properties of the image matrix might be summed up in a broad concept of "compatibility." If the change in the system makes for greater compatibility the system may move to an equilibrium. The "balance-of-power" theory postulates the existence of an equilibrium of this nature. The record of history, however, suggests that, in the past at least, international systems have usually been unstable. The incompatibility of various national images has led to changes in the system which have created still greater incompatibility, and the system has moved to less and less stable situations until some crisis, such as war, is reached, which represents a discontinuity in the system. After a war the system is reorganized; some national units may disappear, others change their character, and the system starts off again. The incompatibility may be of many kinds, and it is a virtue of this kind of rather loose model that the historian can fill in the endlessly various details in the spe- 
cial situations which he studies. The model is a mere dress form on which the historian swathes the infinite variations of fashion and fact.

In the model we can distinguish two very different kinds of incompatibility of images. The first might be called "real" incompatibility, where we have two images of the future in which realization of one would prevent the realization of the other. Thus two nations may both claim a certain piece of territory, and each may feel dissatisfied unless the territory is incorporated into it. (One thinks of the innumerable irredenta which have stained the pages of history with so much blood!) Or two nations may both wish to feel stronger than, or superior to, each other. It is possible for two nations to be in a position where each is stronger than the other at home, provided that they are far enough apart and that the "loss of power gradient" (which measures the loss of power of each as we remove the point of application farther and farther from the home base) is large enough. It is rarely possible, however, for two nations each to dominate the other, except in the happy situation where each suffers from delusions of grandeur.

The other form of incompatibility might be called "illusory" incompatibility, in which there exists a condition of compatibility which would satisfy the "real" interests of the two parties but in which the dynamics of the situation or the illusions of the parties create a situation of perverse dynamics and misunderstandings, with increasing hostility simply as a result of the reactions of the parties to each other, not as a result of any basic differences of interest. We must be careful about this distinction: even "real" incompatibilities are functions of the national images rather than of physical fact and are therefore subject to change and control. It is hard for an ardent patriot to realize that his country is a mental, rather than a physical, phenomenon, but such indeed is the truth! It is not unreasonable to suppose, however, that "real" incompatibilities are more intractable and less subject to "therapy" than illusory ones.

One final point of interest concerns what might be called the impact of "sophistication" or "self-consciousness" on national images and the international system. The process of sophistication in the image is a very general one, and we cannot follow all its ramifications here. It occurs in every person in greater or less degree as he grows into adult awareness of himself as part of a larger system. It is akin almost to a Copernican revolution: the unsophisticated image sees the world only from the viewpoint of the viewer; the sophisticated image sees the world from many imagined viewpoints, as a system in which the viewer is only a part. The child sees everything through his own eyes and refers everything to his own immediate comfort. The adult learns to see the world through the eyes of others; his horizon extends to other times, places, and cultures than his own; he learns to distinguish between those elements in his experience which are universal and those which are particular. Many grown people, of course, never become adults in this sense, and it is these who fill our mental hospitals with themselves and their children.

The scientific subculture is an important agency in the sophistication of images. In the physical world we no longer attribute physical phenomena to spirits analogous to our own. In the social sciences we have an agency whereby men reach self-consciousness about their own cultures and institutions and therefore no longer regard these as simply given to them by "nature." In economics, for instance, we have learned to see the system as a whole, to realize that many things which are true of individual behavior are not true of the system and that the system itself is not incapable of a modicum of 
control. We no longer, for instance, regard depressions as "acts of God" but as systemmade phenomena capable of control through relatively minor system change.

The national image, however, is the last great stronghold of unsophistication. Not even the professional international relations experts have come very far toward seeing the system as a whole, and the ordinary citizen and the powerful statesman alike have naïve, self-centered, and unsophisticated images of the world in which their nation moves. Nations are divided into "good" and "bad"-the enemy is all bad, one's own nation is of spotless virtue. Wars are either acts of God or acts of the other nations, which always catch us completely by surprise. To a student of international systems the national image even of respectable, intellectual, and powerful people seems naïve and untrue. The patriotism of the sophisticated cannot be a simple faith. There is, however, in the course of human history a powerful and probably irreversible movement toward sophistication. We can wise up, but we cannot wise down, except at enormous cost in the breakdown of civilizations, and not even a major breakdown results in much loss of knowledge. This movement must be taken into account in predicting the future of the international system. The present system as we have known it for the past hundreds or even thousands of years is based on the widespread acceptance of unsophisticated images, such as, for instance, that a nation can be made more secure merely by increasing its armaments. The growth of a systems-attitude toward international relations will have profound consequences for the dynamics of the system itself, just as the growth of a systems-attitude in economics has profound consequences for the dynamics of the economic system.

If, as I myself believe, we live in an international system so unstable that it threatens the very existence of life on earth, our main hope for change may lie in the rapid growth of sophistication, especially at the level of the images of the powerful. Sophistication, of course, has its dangers also. It is usually but a hair's-breadth removed from sophistry, and a false sophistication (of which Marxism in some respects is a good example) can be even more destructive to the stability of a system than a naïve image. Whichever way we move, however, there is danger. We have no secure place to stand where we are, and we live in a time when intellectual investment in developing more adequate international images and theories of international systems may bear an enormous rate of return in human welfare. 